\title{
Rare variation in arterial branching of celiac trunk with three aberrant hepatic arteries - Case report
}

\section{RACHANA K. ${ }^{1}$, SAMPATH MADHYASTHA ${ }^{2 *}$,VASUDHA SARALAYA ${ }^{3}$, TERESA JOY ${ }^{3}$, DIVYA PREMCHANDRAN ${ }^{3}$ and SANTHOSH RAI ${ }^{4}$}

\author{
${ }^{1}$ Department of Anatomy, Kasturba Medical College, 576104, Mangalore, Manipal University, INDIA \\ ${ }^{2}$ Additional professor, Department of Anatomy, Kasturba Medical College, Mangalore, INDIA-576104 \\ ${ }^{3}$ Department of Anatomy, Kasturba Medical College, 576104, Mangalore, Manipal University, INDIA \\ ${ }^{4}$ Department of Radiodiagnosis, Kasturba Medical College, 576104, Mangalore, Manipal University, INDIA \\ *E-mail: sampath.m@manipal.edu
}

\begin{abstract}
The celiac trunk shows a trifurcate division which branches to supply the hepatobiliary system, stomach, parts of the digestive tract. The celiac trunk usually exhibits regular pattern of branching with few variations reported. This case report highlights on the vitality of anomalous branching of the celiac trunk and it branches. Surgical complications involving these organs would be partially explained by studying the anomalous branching of the vascular components supplying it. Here we have reported anomalous origin of three aberrant hepatic arteries, one accessory hepatic artery and an aberrant cystic artery. These variations are of importance to radiologists and hepatic surgeons.
\end{abstract}

Keywords: aberrant hepatic artery, anomalous branching, celiac trunk, inferior phrenic artery, cystic artery.

\section{Introduction}

Celiac trunk takes its origin from the ventral aspect of abdominal aorta at level of T12 vertebrae measuring about $1.5 \mathrm{cms}$ to $2 \mathrm{cms}$ from its origin. After its origin it normally trifurcates into left gastric, splenic and the common hepatic artery. The celiac trunk and its branches supplies the gastrointestinal tract (CHEN, YANO, EMURA et al., 2009). The left gastric artery branch of the celiac trunk gives off branches to the stomach and the lower oesphagus in its normal course. The splenic artery takes a tortuous course towards the spleen and ends by supplying the spleen, the pancreas and stomach through the left gastroepiploic and short gastric arteries (STANDRING, 2004). The common hepatic artery gives off branches like the gastro duodenal and hepatic artery proper. The gastro duodenal artery supplies the stomach and part of the duodenum (STANDRING, 2004). The hepatic artery proper gives off right gastric artery and then, divides into right and left hepatic arteries to supply the respective lobes of the liver. The right hepatic branch gives off a cystic artery to supply the gall bladder (STANDRING, 2004).

The variations in the branching of the celiac trunk have been recorded frequently but with differences in the pattern of branching, the vessel diameter or its length (SYLVAN D'SOUZA, VIJAYALAXMI, HEMALATHA et al., 2012). The branching pattern were seen to be bifurcate, trifurcate or quadrifurcate (CHITRA, 2010). The additional branches that were given off by the celiac trunk were referred as collaterals (CIÇEKCIBAŞI, UYSAL, SEKER et al., 2005). According to Michels (1996), the origin of the hepatic artery is categorized into ten different types. Hiatt, Gabbay and Busuttil et al. (1994) described six different types of origins of the hepatic artery from 1000 cases. The classification, which was described by these authors, was more precise and it was universally accepted. However, the case we reported here was different from the classically explained pattern of branching of the hepatic artery.

\section{Case Report}

During routine dissection in an undergraduate teaching session in our institution, we observed a unique anatomical variation in the branching of the celiac trunk and its branches in a 60 years old female cadaver. However, the medical history of the cadaver was not known. The course and the branching pattern of the celiac trunk were dissected carefully and variations were noted and recorded using a digital camera.

The origin of the celiac trunk from the abdominal aorta was normal, about 1.5-2 cms distal to the aortic opening of the diaphragm. The trunk was lengthier than usual and was giving branches at various points.

The right and the left inferior phrenic arteries originated from the celiac trunk about $0.75 \mathrm{cms}$ away from its aortic origin. The right inferior phrenic artery gave a branch to the liver that entered the left lobe of the liver from its inferior surface which was named as the first aberrant hepatic artery (1-AHA) (Figure 1) The left gastric artery arose $3 \mathrm{~cm}$ distal to the origin of celiac trunk and extended towards the oesophageal orifice. Soon it divided into oesphageal and gastric branches and gave an additional branch to the liver, which measured $5.5-\mathrm{cms}$ in length. This was assigned as the second aberrant hepatic artery (2-AHA). This second aberrant hepatic artery was found to enter the liver through the groove for ligamentum venosum (Figure 2).

Further, at a distance of $4.2 \mathrm{~cm}$ away from its origin, the celiac trunk bifurcated into splenic and common hepatic 


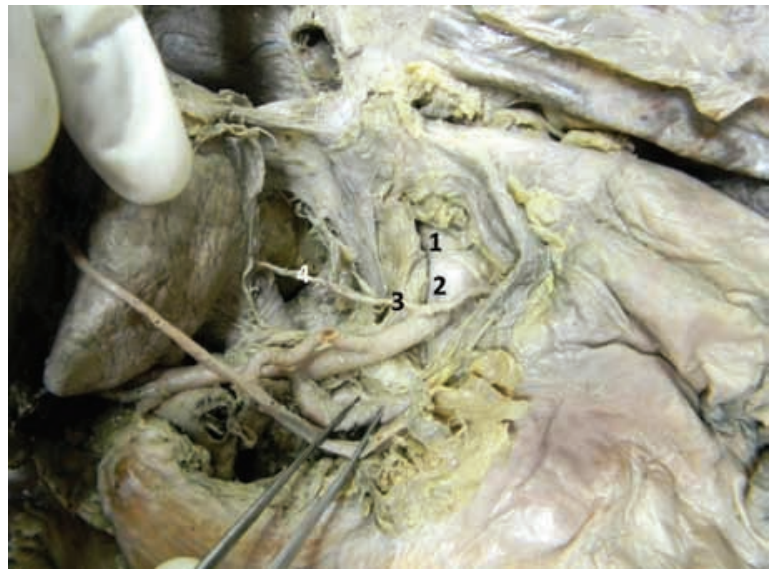

Figure 1. $1=$ Abdominal aorta , $2=$ Coeliac trunk, $3=$ Right inferior phrenic artery, $4=$ First aberrant hepatic artery taking origin from the right inferior phrenic artery.

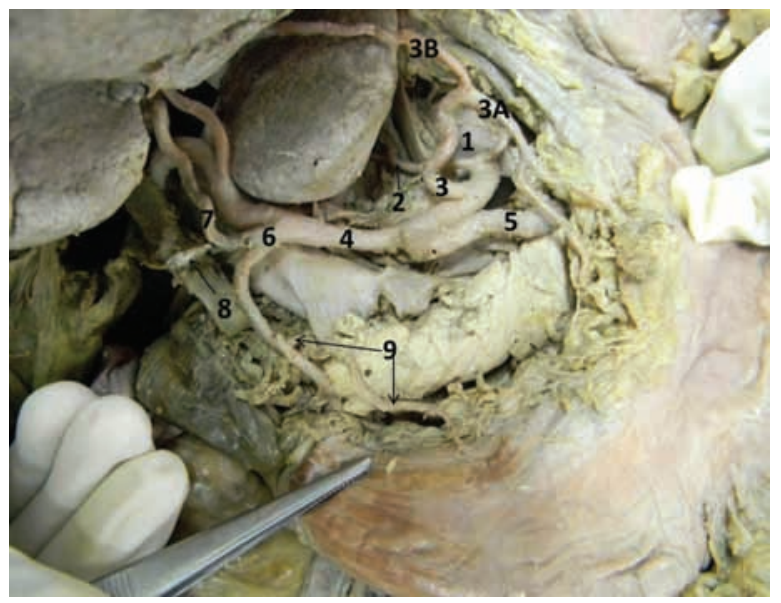

Figure 2. 1 = Coeliac trunk, $2=$ Right inferior phrenic artery, $3=$ Left gastric artery, $3 \mathrm{~A}=$ Branch passing towards lesser curvature of stomach, $3 \mathrm{~B}=$ Second aberrant hepatic artery taking origin from left gastric artery $4=$ Common hepatic artery, $5=$ Splenic artery, $6=$ Gastroduodenal artery, $7=$ Third aberrant hepatic artery from the gastroduodenal artery, $8=$ Aberrant cystic artery, $9=$ Right gastric artery from gastroduodenal artery

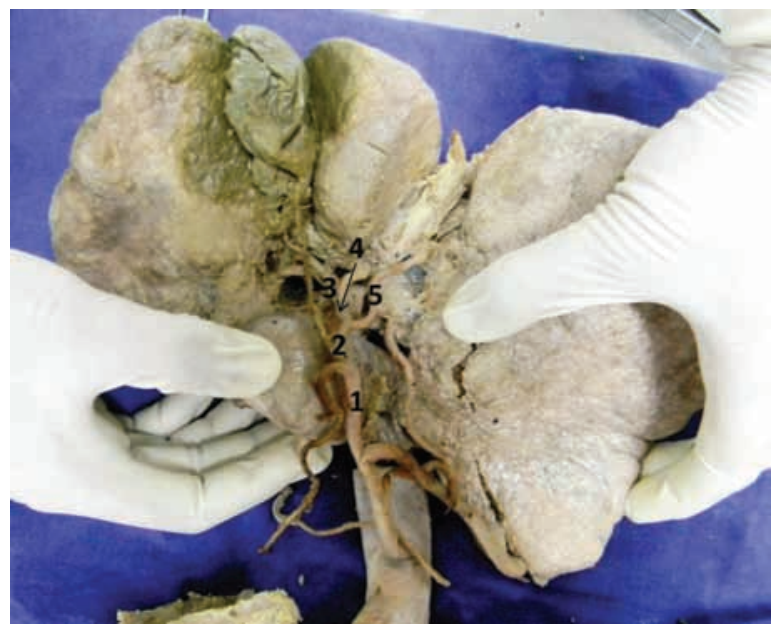

Figure 3. $1=$ Common hepatic artery, $2=$ Hepatic artery proper, $3=$ Right terminal branch of hepatic artery, $4=$ Left terminal branch of hepatic artery, $5=$ Accessory hepatic artery arteries. The splenic artery had a normal origin, course and branching.

The common hepatic artery divided further into a hepatic artery proper and a gastro duodenal artery at a distance of $6.8 \mathrm{~cm}$ from the origin of the celiac trunk, in front of the portal vein (Figure 2).

The gastro duodenal artery took a downward course behind the first part of the duodenum normally. Apart from its usual branches, it gave an additional third aberrant hepatic artery to the liver (3-AHA) and the right gastric artery to the stomach (Figure 2). The right gastric artery had a normal course ascending along the lesser curvature of the stomach while the 3-AHA ascended upwards towards the porta hepatis and gained entry to the liver distance of about $0.75 \mathrm{cms}$ away away from the porta hepatis. The 3 -AHA also gave a thin aberrant cystic branch that gained entry to the gall bladder from its superficial surface in crossing the portal vein from left to right side (Figure 2).

The hepatic artery proper divided into right and left branches $1.4 \mathrm{~cm}$ distal to its origin from the common hepatic artery. The left hepatic was smaller compared to the right hepatic artery. It gave another accessory hepatic branch, which entered the liver along the fissure for ligamentum teres hepatis (Figure 3 ). The large right terminal branch crossed superficial to portal vein and deep to common hepatic duct to reach the porta hepatis. It further divided into 4 branches; one of the branches supplied the gall bladder from the deep surface that coursed normally in the calot's triangle. Remaining three branches from the right terminal branch entered the liver at various points at the porta hepatis itself (Figures 4, 5).

\section{Discussion}

The inferior phrenic arteries owe its importance to its collateral supply to the hepatic segments. It forms a potential anastomosing channel with the hepatic arteries. Apart from its usual targets, the right inferior phrenic artery forms a source of extra hepatic blood supply to the liver (GWON, $\mathrm{KO}$, YOON et al., 2007). The potential communications are typically seen in the caudate lobe and the posterior segment of the liver (YAMAGAMI, KATO, TANAKA et al., 2005). In the present case the 1-aberrant hepatic artery arose from right inferior phrenic artery and entered the inferior surface of the left lobe. According to Couinaud's hepatic segment, classification the caudate lobe is known to receive blood from both right and left terminal branches of the hepatic artery. Further tracing of this aberrant artery would provide more information on its vascular tree within the left lobe and also the specific segment if involved. An abberant hepatic artery (1 AHA) from the right inferior phrenic artery as seen in this case report would also be important because any pathological conditions of the inferior phrenic arteries requiring a radiographic evaluation or during lobar resections, the presence of this aberrant hepatic artery supplying part of the left lobe of the liver should not be missed.

The presence of $2^{\text {nd }}$ aberrant hepatic artery from the left gastric artery as seen in this case has to be noted during surgical divisions of the lesser omentum lest the artery be severed, hampering the blood supply to the liver (SUGAVASI, MANUPATI, BANDI et al., 2012). The branch may also be involved during selective vagotomy through the lesser 


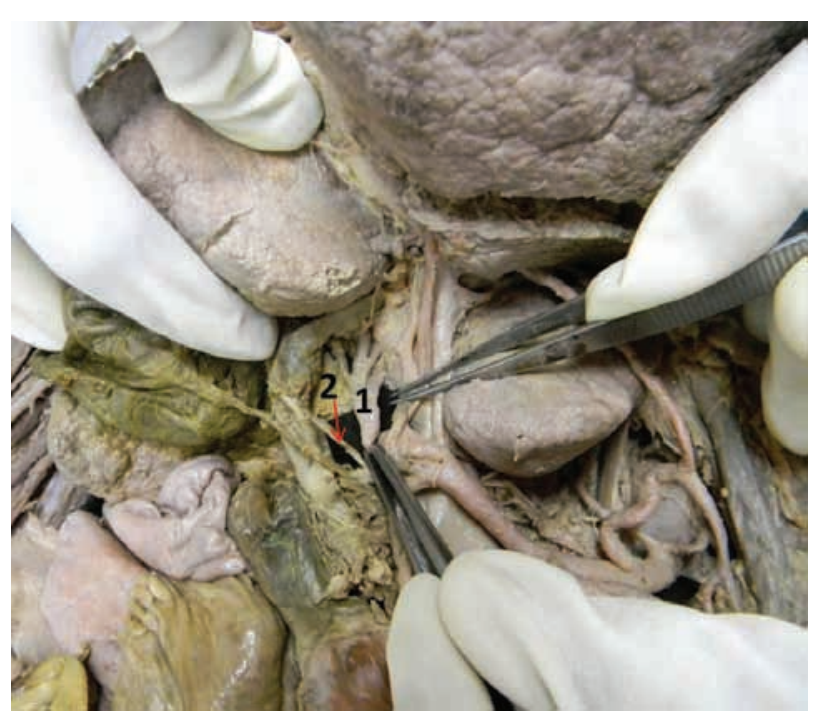

Figure 4. $1=$ Branches from right terminal hepatic artery entering through Portahepatis $2=$ Cystic branch from the right terminal hepatic artery.

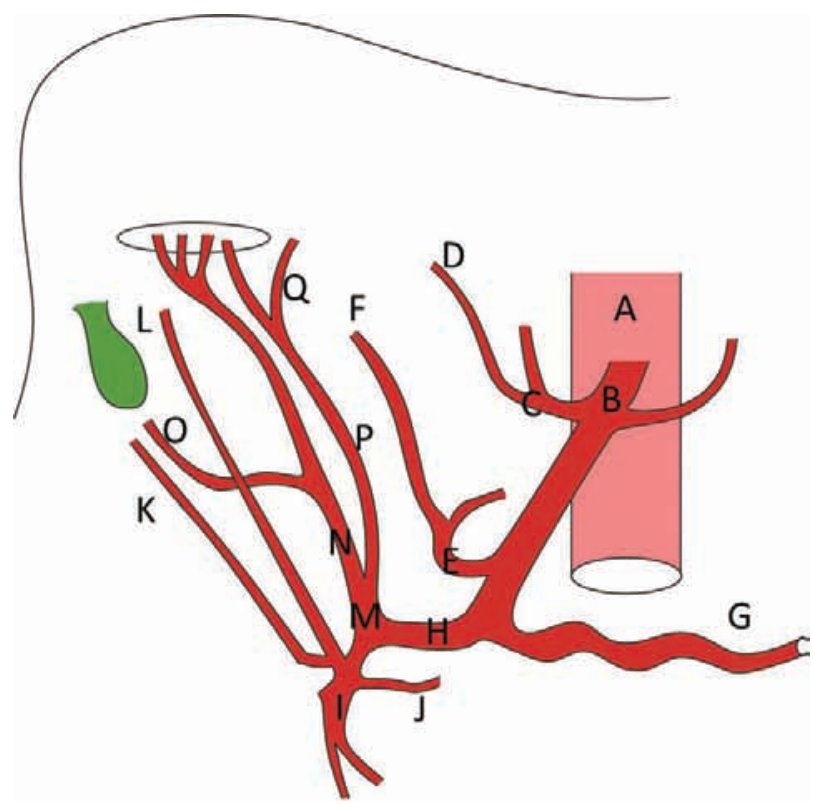

Figure 5. $A=$ Abdominal aorta $B=$ Ceoliac trunk $C=$ Right inferior phrenic artery $\mathrm{D}=$ First aberrant hepatic artery $\mathrm{E}=\mathrm{Left}$ gastric artery $\mathrm{F}=$ Second aberrant hepatic artery $\mathrm{G}=$ Splenic artery $\mathrm{H}=$ Common hepatic artery $\mathrm{I}=$ Gastoduodenal artery $\mathrm{J}=$ Right gastric artery $\mathrm{K}=$ Aberrant cystic artery $\mathrm{l}=$ Third aberrant hepatic artery $\mathrm{M}=$ Hepatic artery proper $\mathrm{N}=$ Right terminal hepatic artery $\mathrm{O}=$ Cystic branch from right terminal hepatic artery $\mathrm{P}=$ Left terminal hepatic artery $\mathrm{Q}=$ Accessory hepatic artery from left terminal hepatic artery.

omentum. Further, the hepatic branch given off by the left gastric artery would sometimes replace the left hepatic artery. It may also course along with the left hepatic artery proper in which case it may be called as accessory left hepatic artery (SUGAVASI, MANUPATI, BANDI et al., 2012). In cases where the left hepatic artery is given by the left gastric artery, if gastrectomy is done in such an individual it can cause liver dysfunction (OKANO, SAWAI, TANIGUCHI et al., 1993). During removal of lymph nodes in radical gastrectomy, the surgeon should take into account the presence of aberrant hepatic artery from the left gastric artery, as in this case would lead to iatrogenic complications (WEIMANN, MEYER, MAUZ et al., 1991). During the laparoscopic treatment of gastro-oesophageal reflux, the presence of an aberrant hepatic artery from the left gastric artery may pose difficulties during surgery and can lead to hepatic necrosis. Hence, a thorough understanding of the possibility of the accessory or an aberrant hepatic artery from the left gastric artery is of importance.

The emergence of the right gastric artery from the gastro duodenal artery as seen in the present case would interfere with the blood supply to the stomach. In cases of upper gastrointestinal bleeding from the ruptured gastro duodenal arteries, embolization surgeries are performed (BURRIS, LIN, JOHNSTON et al., 2009). The presence of third aberrant hepatic artery from gastroduodenal artery may involve in therapeutic arterial embolization surgery of gastroduodenal artery, which may also affect some part of the stomach. Hence, an apt radiological investigation followed by an anastomotic surgery or a ligation has to be performed in cases of embolization surgeries of gastro duodenal arteries. The accessory hepatic artery entered the liver through fissure for ligamentum teres. The course of this artery is important in case of surgeries involving gall bladder.

The hepatic arterial variation in its branching pattern is of importance in the liver transplant surgeries. Of the 24 patients with variant hepatic artery anatomy, five $(20.8 \%)$ had post transplantation hepatic artery complications. In contrast, only two $(3.3 \%)$ of the 60 patients with classic hepatic artery anatomy had complications.

In the present study, an aberrant cystic branch from the third aberrant hepatic artery is of importance in laparoscopic surgeries of the gall bladder and the liver (HIATT, GABBAY and BUSUTTIL, 1994). The orthotropic liver transplantation represents an ideal opportunity to study the surgical anatomy of the blood supply to the liver. The extra hepatic arteries must be identified with precision at the time of liver harvest. A thorough angiographic study of the donors hepatic artery prior to liver transplantation is vital and could be beneficial. The segment of the liver with aberrant hepatic artery or arteries can be harvested, which can be utilized in recipient, which would avoid arterial reconstruction which otherwise usually followed. Hence, the present case has been reported as one of the rare types wherein there were three aberrant and one accessory hepatic artery. This report may throw light on the possible variations of the vascular patterns, which will help radiologists and surgeons to perform an effective liver transplantation, hepatobiliary surgery, hiatal surgery for gastro esophageal reflux and bariatric, gastric and pancreatic surgeries.

\section{References}

BURRIS, JM., LIN, PH., JOHNSTON, WF., HUYNH, TT. and KOUGIAS, P. Emergent embolization of the gastroduodenal artery in the treatment of upper gastrointestinal bleeding: the experience from a surgeon-initiated interventional program. The American Journal of Surgery, 2009, vol. 198, n. 1, p. 59-63. PMid:19178901. http://dx.doi.org/10.1016/j.amjsurg.2008.07.046 
CHEN, H., YANO, R., EMURA, S. and SHOUMURA, S. Anatomic variation of the celiac trunk with special reference to hepatic artery patterns. Annals of Anatomy, 2009, vol. 191, n. 4, p. 399-407. PMid:19540742. http://dx.doi.org/10.1016/j. aanat.2009.05.002

CHITRA, R. Clinically relevant variations of the coeliac trunk. Singapore Medical Journal, 2010, vol. 51, n. 3, p. 216-219. PMid:20428743.

CIÇEKCIBAȘI, AE., UYSAL, II., SEKER, M., TUNCER, I., BÜYÜKMUMCU, M. and SALBACAK, A. A rare variation of the coeliac trunk. Annals of Anatomy, 2005, vol. 187, n. 4, p. 387-391. PMid:16163851.

GWON, DI., KO, GY., YOON, HK., SUNG, KB., LEE, JM., RYU, SJ., SEO, MH., SHIM, JC., LEE, GJ. and KIM, HK. Inferior phrenic artery: anatomy, variations, pathologic conditions, and interventional management. Radiographics, 2007, vol. 27, n. 3, p. 687-705. PMid:17495287. http://dx.doi.org/10.1148/ rg. 273065036

HIATT, JR., GABBAY, J. and BUSUTTIL, RW. Surgical anatomy of the hepatic arteries in 1000 cases. Annals of Surgery, 1994, vol. 220, n. 1, p. 50-52. PMid:8024358 PMCid:PMC1234286. http://dx.doi.org/10.1097/00000658-199407000-00008

MICHELS, NA. Newer anatomy of the liver and its variant blood supply and collateral circulation. The American Journal of Surgery, 1966, vol. 112, n. 3, p. 337-347. http://dx.doi. org/10.1016/0002-9610(66)90201-7

OKANO, S., SAWAI, K., TANIGUCHI, H. and TAKAHASHI, T. Aberrant left hepatic artery arising from the left gastric artery and liver function after radical gastrectomy for gastric cancer. World
Journal of Surgery, 1993, vol. 17, n. 1, p. 70-73. PMid:8447143. http://dx.doi.org/10.1007/BF01655708

STANDRING, S. Gray's anatomy: anatomical basis of clinical practice. 40th ed. New York: Elsevier Churchill Livingstone, 2004. p. 1073.

SUGAVASI, R., MANUPATI, S., BANDI, S., INDIRA, B. and JETTI, R. Origin of left accessory hepatic artery from the left gastric artery in south Indian cadaver: its clinical importance. Anatomy Journal of Africa, 2012, vol. 1, n. 1, p. 10-12.

SYLVAN D'SOUZA, A., VIJAYALAXMI, HEMALATHA, PUGAZHANDHI and MAMATHA, H. Anatomical variations in the Branches of the Coeliac Trunk. Journal of Clinical and Diagnostic Research, 2012, vol. 6, n. 3, p. 333-335.

WEIMANN, A., MEYER, HJ., MAUZ, S., RINGE, B., JAHNE, J. and PICHLAMYR, R. Anatomic variations in the course of the left hepatic artery: a problem for systematic lymphadenectomy in gastrectomy or proximal stomach resection before stomach tube formation. Der Chirurg, 1991, vol. 62, n. 7, p. 552-556. PMid:1935382.

YAMAGAMI, T., KATO, T., TANAKA, O., HIROTA, T. and NISHIMURA, T. Influence of extra hepatic arterial inflow into the posterior segment or caudate lobe of the liver on repeated hepatic arterial infusion chemotherapy. Journal of Vascular and Interventional Radiology, 2005, vol. 16, n. 4, p. 457-463. PMid:15802444. http://dx.doi.org/10.1097/01.RVI.0000152388.97231.75

Received January 24, 2014 Accepted June 23, 2014 